\title{
An overview of grid interface and internal electrical system of a Nuclear Power Plant in Bangladesh
}

\author{
Md Ghulam Zakir ${ }^{*}$ \\ A.Z. M.Salahuddin ${ }^{2}$ \\ Dr,M.A. Rashid Sarkar ${ }^{3}$ \\ ${ }^{* 1}$ Lecturer, Nuclear Science and Engineering (NSE) Department, Military Institute of \\ Science and Technology (MIST), Dhaka, Bangladesh \\ ${ }^{2}$ Head of Nuclear Science and Engineering (NSE) Department, Military Institute of \\ Science and Technology (MIST), Dhaka, Bangladesh \\ ${ }^{3}$ Director, Institute of Nuclear Power Engineering Bangladesh University of \\ Engineering Technology (BUET) Dhaka, Bangladesh
}

This journal is licensed under a Creative Commons Attribution-NonCommercial 4.0 International License (CC-BY-NC). Articles can be read and shared for noncommercial purposes under the following conditions:

- BY: Attribution must be given to the original source (Attribution)

- NC: Works may not be used for commercial purposes (Noncommercial)

This license lets others remix, tweak, and build upon your work non-commercially, and although their new works must also acknowledge you and be non-commercial, they don't have to license their derivative works on the same terms. License Deed Link: http://creativecommons.org/licenses/by-nc/4.0/ Legal Code Link: http://creativecommons.org/licenses/by-nc/4.0/legalcode $A B C$ Research Alert uses the CC BY-NC to protect the author's work from misuse.

\section{Abstract}

This paper describes the interconnection and interface between Nuclear Power plant and electrical grid infrastructure. In its first part, the power grid system in Bangladesh and suitability of building nuclear power plant at Ruppur in Bangladesh is described. The condition for a nuclear power plant to be included to the national grid system is also mentioned. Impact of NPP developer and operator and importance of transmission system operators (TSO) for installment of NPP. In the end of the writing, what types of grid failure could occur and how this grid system can be made more reliable is also described. Moreover, advantage of grid interconnection and site selection assessment of location is briefly mentioned as well.

Keywords

NPP, grid, TSO, trip, blackout.

\section{INTRODUCTION}

Nuclear power offers promise as an energy solution since it produces a huge amount of energy from small amount of fuels. As time go by, nuclear power based industrialization is increasing both in developed and developing countries. Implementation of nuclear power for the first time to a country is always challenging. Building a nuclear based industry is not only depends on the construction of nuclear power plant but also on the development of electrical infrastructure. Thus, a safe, efficient and reliable grid system is prerequisite for the implementation and expansion of the nuclear industry.

A sound grid system is a strong combination of power generation, load distribution and a network to the neighboring countries. Significant modification in grid system is essential for 
the country does not have NPP. Few features of a new grid system for introducing a NPP are cost-effective operation, less instabilities and interruptions in NPP-grid interaction, more productively and consistently supply power to the consumer. According to local grid condition and usage sitting decision must be considered for both NPP and the grid. However, integration of NPP to the national grid is a real engineering challenge. One of the steps of IAEA is to development of electrical grid system to integrate NPP to the national grid.

Several essential features of the grid are adequate capacity for exporting power from NPP, provide safe and economic operation to the NPP since NPP requires safe startup, operation, normal or emergency shutdown of the reactor. Individual organizations are required to be involved with NPP authority or regulatory commission and another organization involved with the grid system. A compatible relation must be built between NPP organization and grid system. Electrical grid system builds a symbiotic relationship between the grid and NPP. Basically, a NPP is used as a 'generator' and 'customer' sequentially. When, NPP supplies electrical energy to the grid, it works as a generator; on the other hand, NPP receives power for safety operation during emergency or any transient condition, on normal startup of NPP. This is how NPP is used as a customer. Both, 'offsite' and 'onsite' power generation are required for safety and precaution purpose of NPP. Onsite power consist of Emergency Diesel Generator System (EDGS) which delivers power to Emergency Core Cooling System (ECCS) in case of any transient situation such as Loss of Coolant Accident (LOCA).Incase of onsite power failure, grid provides offsite power to the NPP.

\section{NUCLEAR POWER PLANT AND OTHER POWER GENERATION SYSTEM CONNECTED TO GRID IN BANGLADESH:}

The rapid development in industrialization sector requires sound and affordable electricity generation system. Current generation capacity is almost $10,500 \mathrm{MW}$ while the target is about 39000MW.A summarized table of generation report on October 22, 2014 is provided here which is collected from the official website of Bangladesh Power Development Board (BPDB) (BPDB, 2011).

\begin{tabular}{|c|c|c|c|}
\hline Owner Name & Derated Capacity (MW) & Day Peak (MW) & Eve. Peak (MW) \\
\hline Power Development Board & 4332.00 & 1767.0 & 2702.00 \\
\hline Electricity Generation Company of Bangladesh Ltd. & 622.00 & 0.00 & 0.00 \\
\hline Ashujganj Power Station Co. Ltd. & 682.00 & 467.00 & 467.00 \\
\hline Independent Power Producers & 1617.00 & 723.00 & 896.00 \\
\hline Small Independent Power Producer & 325.00 & 248.00 & 283.00 \\
\hline Rental Power & 1987.00 & 1269.00 & 1440.00 \\
\hline Other & 825.00 & 1101.00 & 1189.00 \\
\hline Total & 10390.00 & 5515.00 & 6987.00 \\
\hline
\end{tabular}

Table 1: Power generation by different Producer in Bangladesh

$55 \%$ of total power generation is produced from government owned power plant and $45 \%$ of power is generated from private companies. Two different time have been fixed by the government to meet the overall demand of the entire country which are 2021 and 2030.The total demand has been fixed as $39000 \mathrm{MW}$ by 2030 . However, the total power generation from government owned power plant is $55 \%$ while power generation from private owned power plant is $45 \%$ of total generation. The rapid growth of the population in Bangladesh requires more electricity generation. Thus a revised target of additional $12473 \mathrm{MW}$ has been fixed by implementation of different new projects (Generation Plan, 2018). Since, natural gas resources are going to deplete within next few years Bangladesh government is planning to construct Ruppur Nuclear Power Plant (RNPP) for addition of power to the national grid on 2023. 


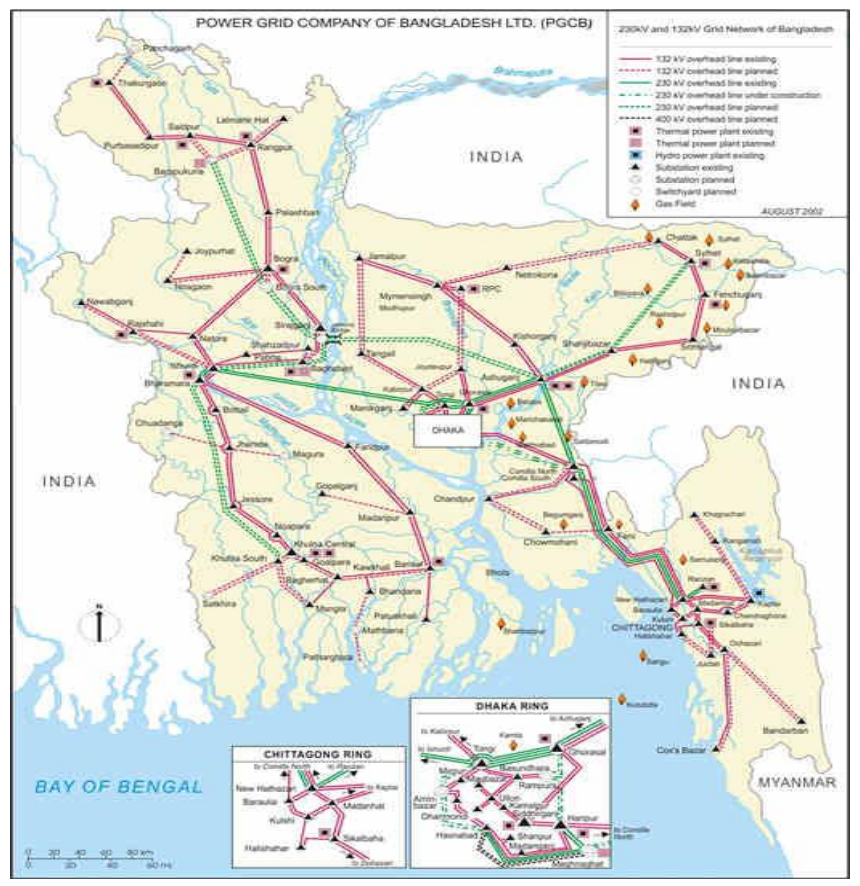

\section{RUPPUR NUCLEAR POWER PLANT (RNPP)}

A nuclear power plants two units of 1200 MW would be built at Ruppur for the Bangladesh Atomic Energy Comission (BAEC) which was signed in 2011. Site works have been started in October 2013, and construction of first unit has been started from 2015 and expecting to be operated soon after 2020.Proposed second unit will start to build by 2020 and will start operation from 2025 [3].

\section{TRANSMISSION VOLTAGES}

According to transmission voltage, transmission voltage is classified into three categories in Bangladesh:

i. $400 \mathrm{KV}$ Transmission Line

ii. 230KV Transmission Line

iii. 132KV Transmission Line

As per PGCB, the Transmission design of Bangladesh National Power Grid up to October 2014 as given below:
i. $\quad 400 \mathrm{KV}$ line $164.70 \mathrm{ckt} \mathrm{km}$
ii. $\quad 230 \mathrm{KV}$ line $3,044.45 \mathrm{ckt} \mathrm{km}$
iii. $\quad 132 \mathrm{KV}$ line $6210 \mathrm{ckt} \mathrm{km}$
iv. $\quad 400 \mathrm{KV}$ substation 1 Nos.500Mw HVDC Back to Back station
v. 230/132 KV substation 18Nos.8775 MVA
vi. 132/33KV substation 88 Nos.11255MVA

Besides, electric power can be transmitted by underground power cables as there is no damage to the cable in case of any extreme weather condition. On the contrary, main disadvantage is its installment cost is very high and cause long time to locate and repair [4].

\section{ELECTRICAL SYSTEM AND CONNECTION ARRANGEMENTS}

In various countries, transmission system is manipulated by one or more control centers: there may be a single control system or several control system all throughout the country. To confirm generation and demand are balanced the frequency, voltage level and power flows must have sufficient safety 
support against anticipated faults. Transmission control center will provide switching operation on transmission circuit to control the operation of the power plants. Transmission grids are normally alternating current (AC), which can readily be transformed to higher or lower voltages. Increasingly, direct current (DC) links are being used for particular projects, particularly undersea cables linking countries or linking offshore wind farms to onshore grids via converter stations. Also high-voltage DC links (HVDC) are becoming more important for long-distance efficient transmission.

Usually grid system will allow $132 \mathrm{kV}$ or higher voltage to connect power plants, however, lower energy sources may connect with $66 \mathrm{kV}, 33 \mathrm{kV}$ or $11 \mathrm{kV}$ voltage, such source could be renewable generation source.

A voltage source converter could be used to connect AC grids with high voltage DC (HVDC) links. This make a connection with asynchronous AC systems. More than 300GW of HVDC transmission would be included to world grids by 2020 .

As nuclear power plants are usually generate a massive power and larger than fossil fuel plants, it can include the generating unit which will $15 \%$ of the reserve capacity of the grid. This is so that plant can be offline state for refueling or maintenance. Moreover, more investment in the grid is required in the power plant.

Two types of grid is build up in terms of frequency control: regulation control smooths out the routine minor load or generation variation; contingency control is change in generation demand balance to avoid large frequency excursions in the networks arising from a major interruption in supply [5].

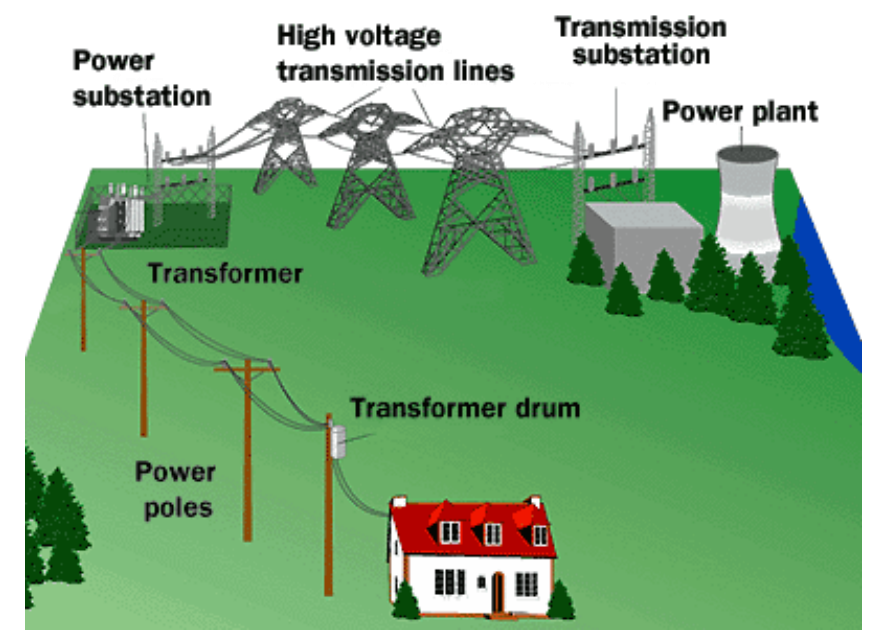

\section{LOAD REDUCTIONS TO THE NPP}

To meet often large demand area during peak hour a part of large load interconnection is opened .NPP should have certain capability to trip certain part of its connection in case of load rejection. When connecting to large NPP with the grid, electrical protection systems are separated during grid interruption, backup power supply such as DC batteries and onsite emergency power sources are used until the grid voltage and restored to the acceptable values. In this case, two physically independent transmission circuits to be built, one for normal operation and one for emergency onsite power system. Two circuit system needs to be independent, testable and redundant.[6][7]

When load is $100 \%$ reduced, all the external loads are suddenly lost or breaker at the station generator output fails ,then the system switched to" house-load" operating mode, which completely separates the NPP .So NPP powers its own auxiliary system and reactor operates at reduced power level to 
only power itself.[6]The key objective in this matter of load rejections is to reduce the reactor power fast enough so that it does not trip and quickly increase the power back to the nominal value .

\section{LOSSES OF GRID FREQUENCY AND VOLTAGE}

Frequency and voltage on the NPP-electric grid system mutually related to each other.As frequency goes down; higher operating voltage is required to start up the system and to continue running. Voltage reduction causes excessive current drawn, in the end results overheating or opening of breakers in the NPP. In this case, automatic generation control (AGC) carefully regulates the voltage and frequency change [8].

NPP usually occupies large portion of the electric grid, a trip can cause large imbalance between power generation and the load. When this occurs, unless more power can be supplied fast enough through external grid connections or by generation, this will decrease the grid voltage or frequency. Reduction in voltage or frequency on the alternate off-site power leads to loss in the offsite power supply to the NPP. Electric grids running at $50-60 \mathrm{~Hz}$ are typically maintained within a very small tolerance $1 \%$. Even small frequency drop due to imbalance between generation and load,can lead to a power trip, which can reduce the longevity of a NPP due to rapid changes power ,pressure and temperature. Steps such as addition of generation sources such as gas turbine or hydraulic power to balance generation vs demand. The grid voltage can also be reduced to meet the frequency requirements though these often lead to "brown outs", which occur when the electric supply is no longer sufficient to cope with normal lighting. Other idea is to control drop in grid frequency include automatically or manually changing outputs by speed governors on the generating unit, and disconnecting selected loads which is called load shedding [6].

\section{NPP DEVELOPERS AND NPP OPERATOR:}

The company operates the NPP, will distinguish NPP from transmission system operator. The key responsibilities of the operator are to ensure the safe operation of the NPP. They must satisfy the necessity of nuclear regulatory authority in the country. In Bangladesh Nuclear Regulatory Authority is working hard to fulfill this purpose [9].

\section{TRANSMISSION SYSTEM OPERATOR (TSO):}

TSO is the company or organization that works for the transmission purpose and connect to the NPP. Depending on the geographical area the number of TSO will be more than one. TSO will cooperate with Energy Ministry and Regulatory Body in the country. The responsibilities of TSO are:

\footnotetext{
1) Impact of changes in electricity demand.

2) Change in design and construction according to the change in electricity demand.

3) In case of failure components maintenance

4) Maintaining a good communication among the neighboring regions and countries.

5) Manipulate the power plant to change the output demand.
}

In some countries, TSO is divided into different organizations who are involved with transmission system owners and some are involved with system operation. It maintains a good communication between transmission system owners and system operators.

\section{STRENGTH OF ELECTRICITY SYSTEM FOR A NUCLEAR POWER PLANT}

After a transient situation electricity supply is required to heat transfer from the reactor .Otherwise, any failure to heat transfer system can cause severe melt down to the fuel core. Amount of heat generation is almost $6.5 \%$ of the power before shut down of the reactor, after one hour it reaches to $1.5 \%$ and it more reduced to $0.4 \%$ after a day. Hence, both offsite and onsite electrical power system takes part to ensure a reliable electrical system for protecting the reactor from overheating situation inside the reactor. Primary reactor safety systems are corresponding with [10]: 
1) Control of Reactivity

2) Transport of heat from the core

3) Confinement of radioactive material

4) Control of operational discharge

5) Accidental release

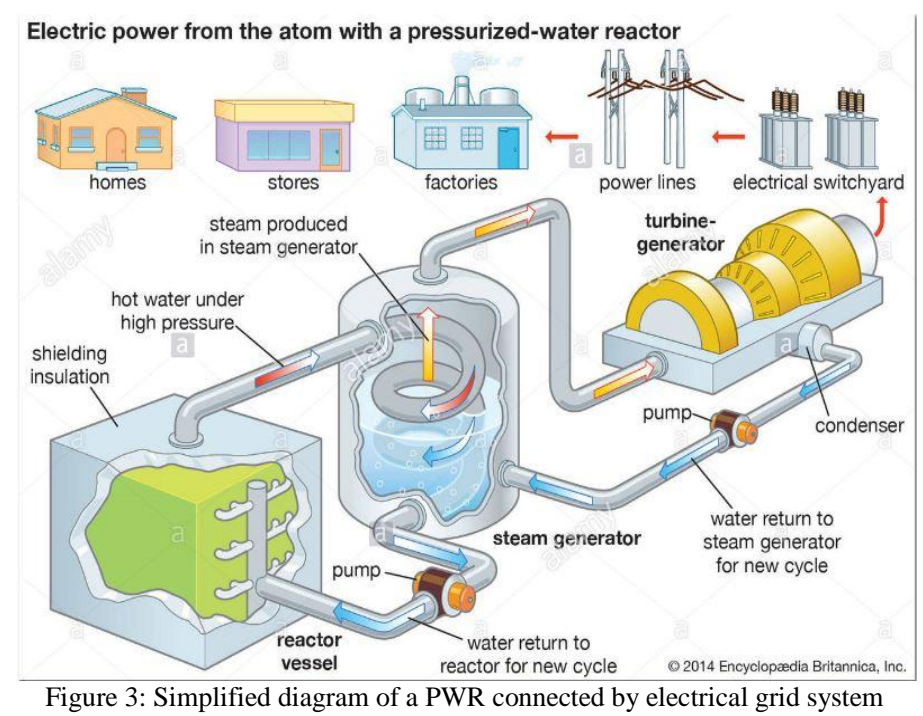

An reliable electricity system which can perform above functions both on emergence and normal operation case is prerequisite for building a NPP. Hence, a robust and reliable electrical system is required not only for safety purpose but also all modes of operation: startup, normal operation, during and after reactor shut down. This dependence on electrical system reveals the requirement of multiple source of electricity: minimum two connection from the transmission system to the NPP (Offsite Power Source) and combinations batteries, diesels and small gas turbines (Onsite Power Source) [11].

\section{ELECTRIC GRID SYSTEM TRIP AND BLACKOUT}

The grid must maintain a constant frequency. As, all the households and industries are interconnected together an ordinary failure in the system can cause huge damage. Large power failure can be eliminated by trip protective circuit breakers since all power plants are interconnected together. As a result, a stable grid system must be constructed so that all NPP's must operate precisely altogether. A grid failure can even cause whole country into blackout and cause even damage to the NPP's. In North America, total twenty power plants have been disconnected because of improper electrical system. Most often, entire electric system fails when a natural disaster occurs such as tornadoes, hurricanes, earthquakes and ice storms.

\section{EMERGENCE ON GRID RELIABILITY}

Transmission system is considered as more dependable and consistent source of power to the offsite power system. A transmission system has better availability as it connects diverse and multiple generators to the transmission system. Thus, NPP's much deal with offsite power as primary source for cooling down the reactor during normal and emergency shutdown. However, the grid reliability is defined as the measure of unirreptable power supply to the NPP with sufficient capacity as well as with adequate voltage and supply. A loss of power from the transmission system can cause loss of AC power to the safety and no safety busses 
at a NPP which relates loss of offsite power (LOOP), tribune trip as well as onsite power failure .Thus, a blackout situation occurs inside the plant. By the risk assessment process the impact of station blackout to the core damage probability is calculated [12].A fault on a grid system from a large distance can cause both offsite power failure to the NPP and cause reactor trip as well. $[13,14]$

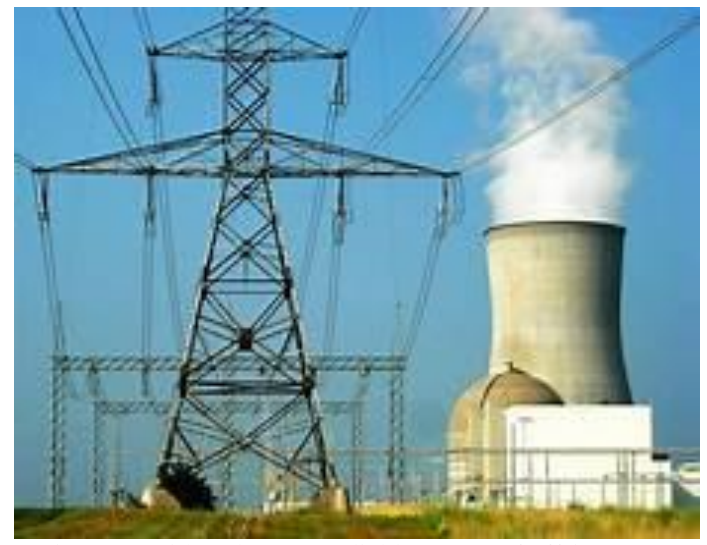

Figure 4:Grid as the most reliable source of offsite power

\section{GRID FAULTS AND POWER SYSTEM RELIABILITY STANDARDS}

Electrical circuits deals with various protection system that usually switched out an item of the faulty part of transmission. This process can occur automatically by the electrical protection system or manually by the system operator. Literally, some faults disconnect the load or generation. Some reasons of the grid fault:
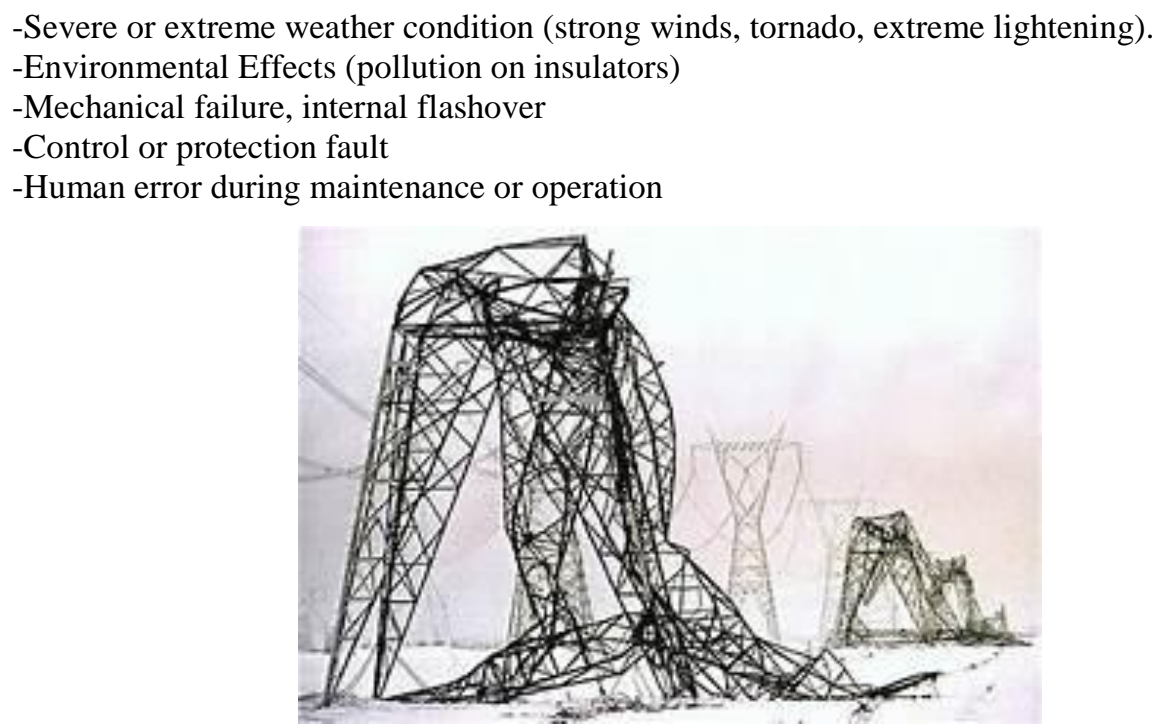

Figure 5:Grid damage due to extreme weather condition

Grid system is required to design in such a way that in case of any severe faults, the system can be recovered and there must be redundant equipment which reconnects the system after a short delay. It is common phenomenon to implement some code or standards to manipulate the electricity system. These codes are used to ensure the correctness of system design. The impact of severe minimum standards for security and reliability to protect the entire system by redundancy to any single event such as: 
-Trip of a single generating unit

-Short circuit or earth fault to over headlines

-Short circuit fault to underground lines

-Fault on bus bar

-Failure of any grid transformer

The system is verified as secure if an event which does not cause any consequence such as:

-Frequency above the normal range

-Voltage above the normal range

-Overloading of transmission circuits

-Cascade tripping of transmission circuits

-Loss of synchronism between two parts of the network

The transmission system requires redundancy for maintenance reason which is a regular requirement. Moreover, a short period of extreme weather condition may cause trip to the several grids at a time. On such a case, more than normal range of frequency and outside the normal range of voltage helps to test the overloading situation for a short period of time so that more serious transient situation of cascade tripping and loss of synchronism will not be possible to occur[15].

\section{ADVANTAGE OF GRID INTERCONNECTIONS}

If several countries are interconnected to each other by a large regional grid system where a nuclear power plant is also included to the system, the grid must be built in such a way that it will be reliable and to have enough capacity to carry the additional power flow after the trip of nuclear power plant. In case of such failure neighboring countries must cooperate to operate their grid system with enough generation units in automatic frequency control mode. Moreover, proper legal and commercial agreements are also required among those countries. A common grid system among different countries can regulate the power distribution proportional to the generation and demand among the countries [16].

\section{SITE SELECTION AND ASSESSMENT:}

The proper site selection for building a nuclear power plant is not a simple process. It depends on different factors such as technical specification, public policy and local environmental laws. Moreover, the factors also include technical and economic aspects of installing the electrical grid.

Following steps are required to select proper site which are collected from the references [17] and [18]:

1) Step One: Regional Analysis: The main purpose is to exclude the improper areas and to select appropriate sites. The analysis is based on the documents such as geographical, geological, hydrological, seismic data, satellite photos.

2) Step two: Screening of potential sites: More comparison has been made by decent investigations which are significant disadvantage and more aspects.

3) Step three: Comparison and ranking: Selection of more appropriate place by overall judgment from a suitable list.

\section{CONCLUSIONS}

This paper briefly describes on the impact of grid connection to the NPP as well as effect of NPP to the grid system. As Bangladesh is going to step into a new era of power generation by dealing with Russian Government for building Ruppur Nuclear Power Plant, a reliable, robust and safe grid infrastructure is important to develop. 
Moreover, TSO can be implemented in the grid system so that NPP will always remain attached with high voltage transmission system both in normal and fault condition. This paper mainly focuses on the combination of TSO and NPP from very beginning stage of designing. In addition to this, the additional expenditure for developing the control of voltage and frequency to include a new nuclear power plant to the grid system where the country not yet has nuclear power plant. More features such as building new transmission connections to the neighboring countries are also explained in this paper. Some other points such as grid faults on extreme weather, advantage of grid connection and site selection and proper land assessment is illustrated in the end of the paper.

\section{Acknowledgement:}

I would like to thank Professor Dr. M.A.Rashid Sarkar to guide me while writing this paper. Without his inspiration it would not be possible to write the entire paper. Also I would like to thank head of my department A. Z. M. Salahuddin for always inspiring me to write a paper.

\section{References}

BPDB (2011)Owner wise daily generation report.

Available at:http://www.bpdb.gov.bd/bpdb/index.php?option=com_content\&view=article\&id=193\&Itemid=120

Generation Plan, (2018)Power Division, Ministry of Power, Energy and Mineral Resources, Government of the people's republic of Bangladesh. Available at: http://www.powerdivision.gov.bd/user/brec/4 1/58

Nuclear power in Bangladesh.(2016)

Available at:http://www.world-uclear.org/info/Country- Profiles/Countries-A-F/Bangladesh

Mr.AlamgirMollh Robin National Power Grid of Bangladesh.

World Nuclear Association (2016).

http://world-nuclear.org/information-library/current-and-future-generation/electricity-transmission-grids.aspx

O. Glöckler, "Interfacing Nuclear Power Plants With the Electric Grid: The Need for Reliability Amid Complexity," International Atomic Energy Agency, June 2009.

J. H. Bickel, "Grid Stability and Safety Issues Associated with Nuclear Power Plants," Evergreen Safety and Reliability Technologies, 14 May 01.

B. Kirby et. al., "Nuclear Generating Stations and Transmission Grid Reliability," Proc. 39th North American Power Symposium, NAPS '07, IEEE 4402323, 30 Sep 07.

INTERNATIONAL ATOMIC ENERGY AGENCY, Fundamental Safety Principles — Safety Fundamentals, IAEA Safety

Standards Series No. SF-1, IAEA, Vienna (2006).

INTERNATIONAL ATOMIC ENERGY AGENCY, Safety of Nuclear Power Plants: Design, IAEA Safety Standards Series, No. NS-R-1, IAEA, Vienna (2000).

UNITED STATES NUCLEAR REGULATORY COMMISSION (2006), General Design Criteria for Nuclear Power Plants - Criterion 17 - Electric Power Systems, 10CFR50 Appendix A, USNRC Washington DC USA.

UNITED STATES NUCLEAR REGULATORY COMMISSION,( 2005) Re-evaluation of Station Blackout Risk at Nuclear Power Plants, NUREG/CR-6890, USNRC Washington DC.

UNITED STATES NUCLEAR REGULATORY COMMISSION, (2005)Three-Unit Trip and Loss of Offsite Power at Palo Verde Nuclear Generating Station, NRC Information Notice 2005-15, USNRC, Washington DC

UNITED STATES NUCLEAR REGULATORY COMMISSION, (2005).Loss of Offsite Power and Dual-Unit Trip at Catawba Nuclear Generating Station, NRC Information Notice 2007-14, USNRC, Washington DC (2007).

UNION FOR THE COOPERATION IN THE TRANSMISSION OF ELECTRICITY (UCTE), (2009) UCTE Operation Handbook -Appendix 3 - Operational Security, ENTSO-E / UCTE, Brussels

UNION FOR THE COOPERATION IN THE TRANSMISSION OF ELECTRICITY (UCTE), (2009)UCTE Operation Handbook - Policy 1 - Load-Frequency Control and Performance, ENTSO-E/ UCTE, Brussels .

ELECTRIC POWER RESEARCH INSTITIUTE, (2002) Siting Guide: Site Selection and Evaluation Criteria for an Early Site Permit Application, Reference 1006878, EPRI, Palo Alto, California, USA.

INTERNATIONAL ATOMIC ENERGY AGENCY,(2003) Site Evaluation for Nuclear Installations — Safety Requirements, IAEA Safety Standards Series No. NS-R-3, IAEA, Vienna 